\title{
A Tickling in the Ear
}

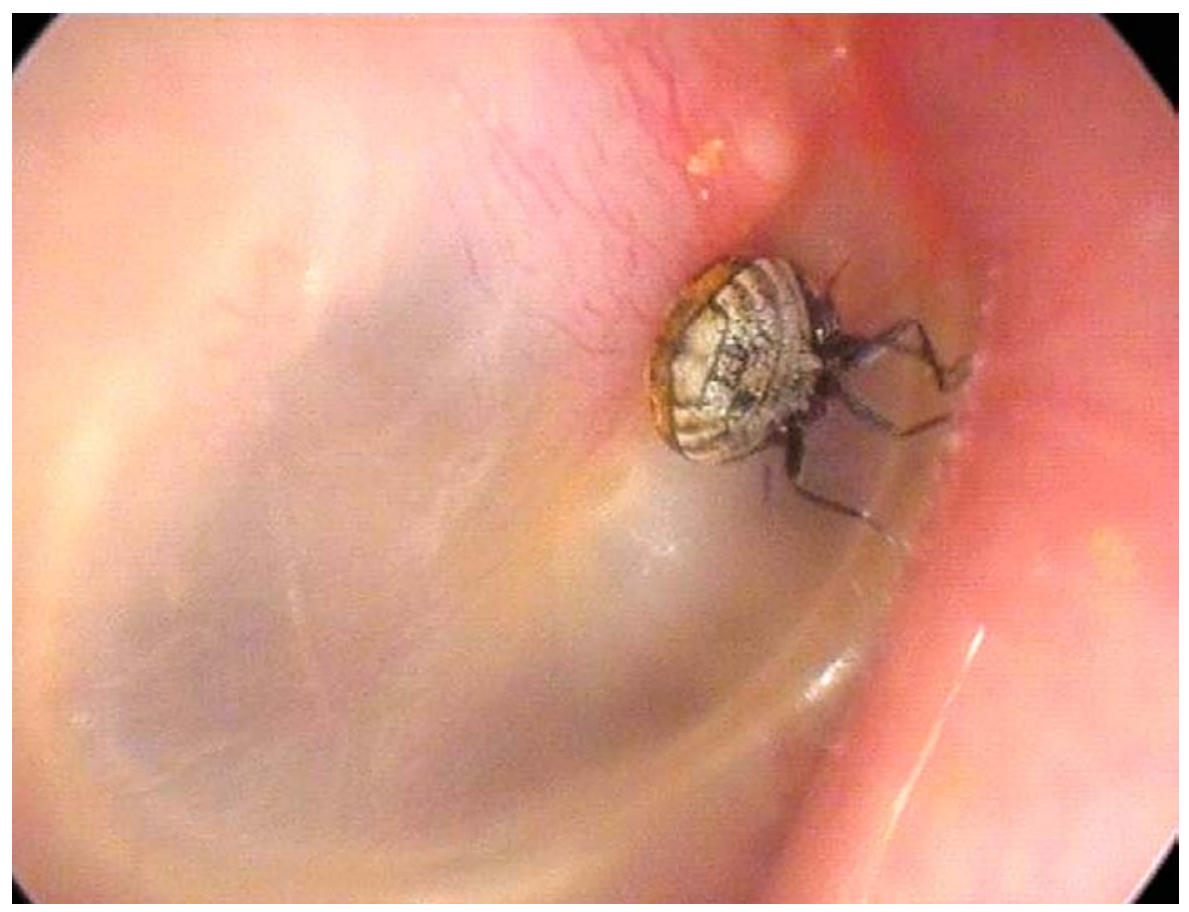

63-YEAR-OLD MAN PRESENTED WITH ACUTE PRURITUS AND BUBBLING tinnitus in his right ear, without hearing loss. Otoscopy revealed a bug anchored to the anterosuperior portion of the right tympanic membrane. The bug was removed by suction after a topical anesthetic agent was applied to the patient's ear. The tinnitus resolved immediately. Aside from mild hyperemia, no visible damage to the tympanic membrane was observed. Insects can be found as foreign bodies in the outer ear canal. The differential diagnosis for acute tinnitus and pruritus without hearing loss should prompt evaluation for a foreign body in the outer ear canal. Two weeks after presentation, this patient had a normal tympanic membrane.
Andreas Arnold, M.D.

Bern University Hospital Bern, Switzerland andreas.arnold@insel.ch

Wolfgang Arnold, M.D.

Technical University of Munich Munich, Germany

This article was updated on January 3 , 2013, at NEJM.org.

DOI: $10.1056 /$ NEJMicml114612

Copyright (@) 2012 Massachusetts Medical Society. 